\title{
OS CÓDIGOS ALFANUMÉRICOS DA BASE NACIONAL COMUM CURRICULAR (BNCC) PARA A EDUCAÇÃO INFANTIL E AS BRINCADEIRAS DAS CRIANÇAS
}

\author{
Camilla Borini Vazzoler GONÇALVES ${ }^{i}$ \\ Janete Magalhães CARVALHO ${ }^{\text {ii }}$
}

\begin{abstract}
RESUMO
Objetiva-se problematizar a brincadeira nos centros de educação infantil, de maneira a cartografar os modos pelos quais as crianças ocupam, criam fabulações e inventam nos espaços-tempos escolares que experienciam. Discutem-se a excessiva psicologização e a pedagogização das brincadeiras das crianças expressas na Base Nacional Comum Curricular (BNCC), pela transcrição de suas aprendizagens e brincadeiras em códigos alfanuméricos. Utiliza-se como metodologia a cartografia das fabulações e brincadeiras das crianças em uma escola municipal de educação infantil. Conclui-se que as fabulações e invenções das crianças levam a pensar a brincadeira como uma condição de nossa animalidade, como instinto e como potência para a criação e aprendizagem.
\end{abstract}

PALAVRAS-CHAVE: BNCC; Códigos alfanuméricos; Educação infantil; Brincadeira.

THE ALPHANUMERIC CODES OF THE NATIONAL COMMON CORE CURRICULUM (BNCC) FOR THE EARLY CHILDHOOD EDUCATION AND THE CHILDREN'S GAMES

\begin{abstract}
It aims to question the game in early childhood education centers, in order to map the ways in which children occupy, create fabulations and invent in the school spacetimes that they live. It discusses the excessive psychologization and pedagogization of children's games, expressed in the National Common Core Curriculum (BNCC), through the transcription of their learning and games in alphanumeric codes. It uses as a methodology the cartography of the children's games in a municipal early childhood education center. It concludes that the children's fabulations and inventions suggests the game as a condition of our animality, as instinct and power for creation and learning.
\end{abstract}

KEYWORDS: BNCC; Alphanumeric codes; Early childhood education; Game.

\footnotetext{
${ }^{\mathrm{i}}$ Doutoranda em Educação pelo Programa de Pós-Graduação em Educação na Universidade Federal do Espírito Santo (UFES). E-mail: camillavazzoler@ gmail.com - ORCID iD: https://orcid.org/0000-0003-2659-1374.

ii Pós-Doutorado em Currículo pela Universidade do estado do Rio de Janeiro e Sociologia da Vida Cotidiana pela Universidade de Lisboa. Doutorado em Educação pela Universidade Federal do Rio de Janeiro. Professora do Programa de Pós-Graduação em Educação da Universidade Federal do Espírito Santo (PPGE/UFES). E-mail: janetemc@terra.com.br - ORCID iD: http://orcid.org/0000-0001-9906-2911.
} 


\section{LOS CÓDIGOS ALFANUMÉRICOS DE LA BASE CURRICULAR COMÚN NACIONAL (BNCC) PARA LA EDUCACIÓN DE LA PRIMERA INFANCIA Y LOS JUEGOS INFANTILES}

\section{RESUMEN}

Su objetivo es problematizar el juego en los Centros de Educación de la Primera Infancia, a fin de mapear las formas en que los niños ocupan, crean fabulaciones e inventan en los espaciotiempos escolares que experimentan. En él se analiza la excesiva psicologización y pedagogización de los juegos de los niños, expresado en la Base Curricular Común Nacional (BNCC), transcribiendo su aprendizaje y juego en códigos alfanuméricos. Utiliza como metodología la cartografía de las fabulaciones y juegos de niños en una escuela municipal de educación infantil. Concluye que las fabulas e invenciones de los niños llevan a pensar en el juego como una condición de nuestra animalidad, como instinto y como un poder para la creación y el aprendizaje.

PALABRAS CLAVE: BNCC; Códigos Alfanuméricos; Educación Infantil; Juegos.

\section{INTRODUÇÃO - BRINCAR É ATITUDE PERMITIDA APENAS COM HORA MARCADA?}

Os discursos entrecruzados de nossas passagens pela educação, em especial pela educação infantil, ecoam referindo-se à importância e à necessidade do brincar. De modo sistematicamente repetido, afirmam: na educação infantil as interações e as brincadeiras fazem parte das atividades pedagógicas; as crianças precisam brincar; as crianças aprendem brincando.

Evidentemente, não podemos negar que as brincadeiras compõem a vida das crianças e dos centros de educação infantil. Embora se reconheçam a importância do brincar, há também uma necessidade quase enlouquecedora de descrição da intensidade da vida infantil. Assim, descreve-se e explica-se incansavelmente como as crianças brincam, os porquês de tal brincadeira, os motivos pelos quais brincam de um jeito e não de outro ou, ainda, como deve ser a brincadeira em certa idade e o que elas devem aprender com alguma brincadeira definida. São inúmeras as situações que estabelecem onde se pode brincar e onde se deve aprender. Não é raro o enquadramento da brincadeira em metas e objetivos de aprendizagem. Nesse sentido, o brincar é pensado como um mecanismo para aprender, como se fosse possível descrever um plano com estratégias, metas e avaliações para que determinada brincadeira produza uma aprendizagem fixada a priori para todas as crianças. 
Descrever como e por que as crianças brincam é uma prática comum e corriqueira nos centros de educação infantil. Nunca faltam oportunidades de perguntar às crianças do que estão brincando ou por que estão brincando de alguma coisa. O pensamento de que as crianças brincam para entender o mundo dos adultos é, muitas vezes, lembrado e reafirmado, retumbando sem fim pelas paredes dos centros de educação infantil. Produz-se, assim, um regime de enunciabilidade dos dispositivos de controle, no qual o brincar se refere sempre ao mundo adulto.

Esses regimes de enunciados também aparecem nos documentos oficiais, como a Base Nacional Comum Curricular (BNCC), repercutindo uma necessidade de descrição, psicologização e pedagogização do brincar. Conforme mencionamos, esses modos de pensar a brincadeira estão encarnados no corpoescola, por isso, em muitos momentos, a brincadeira livre é considerada mera perda de tempo.

No item do documento oficial que busca problematizar "Os objetivos de aprendizagem e desenvolvimento para a educação infantil” (BRASIL, 2018, p. 40), há a seguinte descrição: “[...] as aprendizagens essenciais compreendem tanto comportamentos, habilidades e conhecimentos [...], sempre tomando as interações e a brincadeira como eixo estruturante. Essas aprendizagens, portanto, constituem-se como objetivos de aprendizagem e desenvolvimento" (BRASIL, 2018, p. 40 - grifo nosso).

As brincadeiras, nesse sentido, são entendidas como possibilidades de intervenção pedagógica, uma vez que estão intimamente atreladas a objetivos que visam à aprendizagem e ao desenvolvimento. Novamente, percebemos um discurso que ecoa sobre as crianças para que alcancem etapas e metas no desejo de atingir as aprendizagens "essenciais".

Que aprendizagens seriam essas? É possível identificar o que é essencial para o aprendizado? Como definir o signo que vai afetar um corpo intensivo? Só se brinca interagindo? Interagir com quem e com quê?

Parece que o documento supõe algumas respostas a essas questões, dado que a intensidade de brincar pode ser definida por códigos. Eis alguns exemplos: Código EI01EO02: "Perceber as possibilidades e os limites de seu corpo nas brincadeiras e interações das quais participa" (BRASIL, 2018, p. 41); Código EI01TS03: "Explorar diferentes fontes sonoras e materiais para acompanhar brincadeiras cantadas, canções, músicas e melodias” (BRASIL, 
Programa de Pós-Graduação em Educação: Currículo

2018, p. 44); Código EI03EF02: "Inventar brincadeiras cantadas, poemas e canções, criando rimas, aliterações e ritmos" (BRASIL, 2018, p. 45).

Sim, o documento anseia por descrever e encaixotar as brincadeiras das crianças em códigos. Vejamos um exemplo apresentado pela BNCC na seguinte figura:

\begin{tabular}{|c|c|c|}
\hline \multicolumn{3}{|c|}{ OBJETIVOS DE APRENDIZAGEM E DESENVOLVIMENTO } \\
\hline Bebès (zero a 1 ano e 6 meses) & $\begin{array}{l}\text { Criancas bem pequenas ( } 1 \text { ano } e \\
7 \text { meses a } 3 \text { anos e } 11 \text { meses) }\end{array}$ & $\begin{array}{l}\text { Criancas pequenas ( } 4 \text { anos a } \\
5 \text { anos e } 11 \text { meses) }\end{array}$ \\
\hline $\begin{array}{l}\text { (ElOITSO1) } \\
\text { Explorar sons produzidos com o } \\
\text { proprio corpo e com objetos do } \\
\text { ambiente. }\end{array}$ & $\begin{array}{l}\text { (EIO2TSO1) } \\
\text { Criar sons com materiais, objetos } \\
\text { e instrumentos musicais, para } \\
\text { acompanhar diversos ritmos de } \\
\text { música. }\end{array}$ & $\begin{array}{l}\text { (ElOzTSO1) } \\
\text { Utilizar sons produzidos por } \\
\text { materiais, objetos e instrumentos } \\
\text { musicais durante brincadeiras de } \\
\text { faz de conta, encenaçóes, criaçסes } \\
\text { musicais, festas. }\end{array}$ \\
\hline
\end{tabular}

Como é possivel observar no exemplo apresentado, cada objetivo de aprendizagem e desenvolvimento é identificado por um código alfanumérico cuja composição é expliçada a seguir:

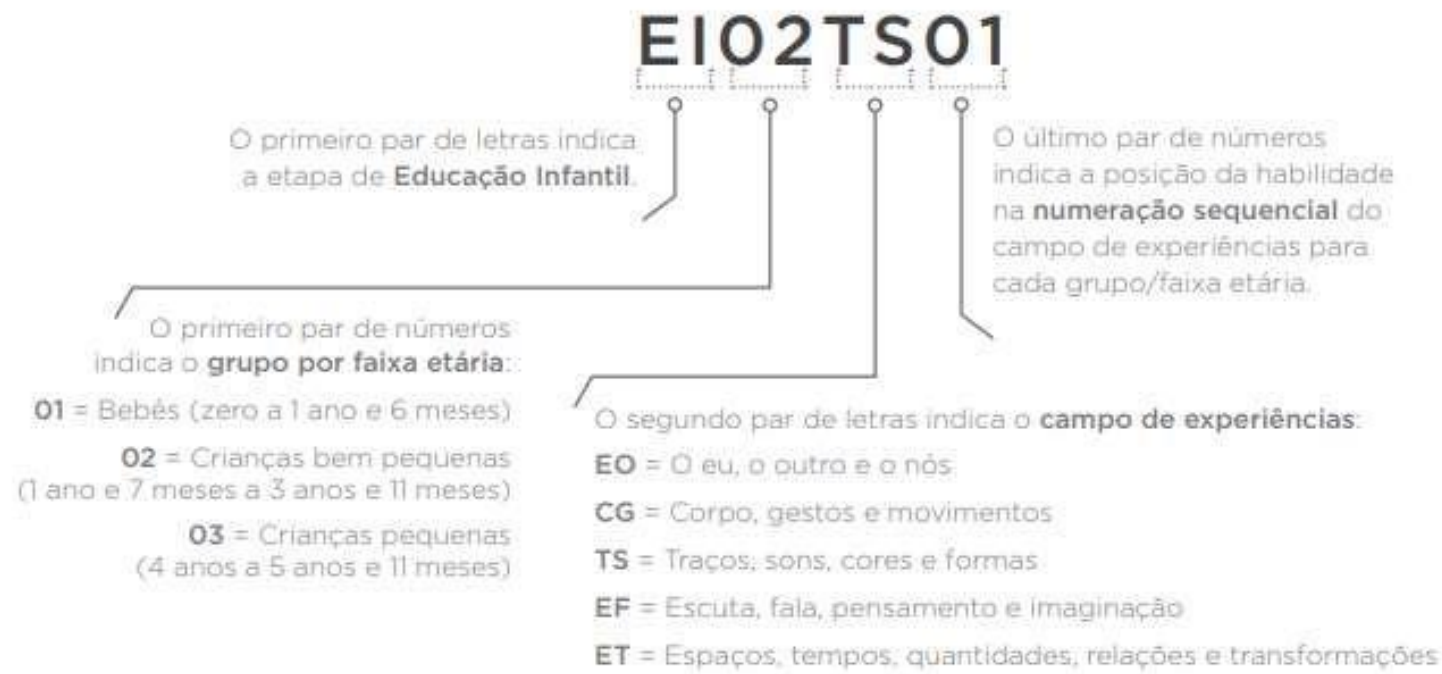

Figura 1 - Campo de experiências "traços, sons, cores e formas": decifrando o código Fonte: Brasil (2018, p. 26).

Entretanto, que referência é essa em que é possível codificar as aprendizagens das crianças? Por quais motivos aprender se refere sempre a um mundo projetado no futuro? Por 
que o adulto tenta descrever as brincadeiras com base em seu próprio mundo? Qual o motivo de tanta vontade de descrição das brincadeiras infantis?

Somos provocados por esses questionamentos. Ao apostarmos em currículos produzidos com as/pelas crianças, acreditamos que elas criam mundos e fabulam, produzem, mas tais agenciamentos não cabem somente ao campo da cognição. Por esse motivo, colocamos em problematização a questão das brincadeiras associadas apenas ao sujeito cognoscente. Todavia, espertas e criativas que são, as crianças sempre burlam os mecanismos de controle, embaralham os códigos que anseiam por defini-las e indicam-nos novas possibilidades de criação e fabulação.

Metodologicamente, buscamos caminhar pelos mapas intensivos e extensivos criados pelas crianças, cuja cartografia serviu como caminho pelo qual procuramos perscrutar as dobras produzidas por elas. Ao nos colocarmos em uma condição de construção metodológica com as crianças, e não sobre elas nem para elas, é quase que percorrer um labirinto que não é nosso. Não se trata do caminho que o cartógrafo fará sozinho, e sim da maneira como a multidão de subjetividades que habitam o espaço escolar vai indicar ao cartógrafo o caminho, pelo qual se afetam as intensidades que transpassam seu corpo vibrátil. Nesse sentido, Guattari e Rolnik (2005, p. 245) salientam que “[...] devemos estar sempre dispostos a guardar nossas próprias cartografias na gaveta e inventar novas cartografias dentro da situação em que nos encontramos".

Portanto, objetiva-se problematizar as relações de saber e poder que, macro e micropoliticamente, atuam nos corpos coletivos potencializando uma vida em composição com forças heterogêneas, no caso, as dobras entre as políticas curriculares emanadas em nível macro e as micropolíticas ativas manifestas nas fabulações e brincadeiras das crianças.

Cumpre frisar que a fabulação efetua uma escrita mais próxima à literatura. Pesquisamos com as crianças e, nos encontros com elas, fabulávamos entre cenas e conversas. Evidentemente, pensávamos na fabulação como resistência, como invenção de um povo menor (DELEUZE; GUATTARI, 2014).

Sendo assim, caminhamos pelas passagens labirínticas de um centro de educação infantil, munidas de nossos equipamentos metodológico-epistemológicos, máquina fotográfica e caderno de campo. Desejamos, com isso, cartografar as paisagens em transformação, os fluxos, as potências, as aprendizagens, as brincadeiras, as linguagens, os conhecimentos e os 
Programa de Pós-Graduação em Educação: Currículo

movimentos afetivos produzidos, a fim de fabular com as crianças outros modos de pensar os currículos, em sua relação/dissonância com as políticas curriculares governamentais em ação.

\section{A MODULAÇÃO DAS APRENDIZAGENS DAS CRIANÇAS NA BNCC}

A BNCC para a educação infantil parece assumir o pressuposto de que sabemos tudo sobre elas. Há, assim, uma naturalização dos discursos majoritários de modo conveniente para que todas as crianças atinjam a aprendizagem ideal. Para tanto, entregamos mapas decalcados para guiá-las uniformemente pelo labirinto escolar.

O documento afirma, de forma explícita, sobre a educação básica:

Reconhece, assim, que a Educação Básica deve visar à formação e ao desenvolvimento humano global, o que implica compreender a complexidade e a não linearidade desse desenvolvimento, rompendo com visões reducionistas que privilegiam ou a dimensão intelectual (cognitiva) ou a dimensão afetiva. Significa, ainda, assumir uma visão plural, singular e integral da criança, do adolescente, do jovem e do adulto - considerando-os como sujeitos de aprendizagem - e promover uma educação voltada ao seu acolhimento, reconhecimento e desenvolvimento pleno, nas suas singularidades e diversidades (BRASIL, 2018, p. 14).

No trecho citado, parece haver uma superação da linearidade da aprendizagem, defendendo que cada criança ou jovem podem caminhar a seu modo, conseguindo, assim, modificar e manipular o mapa decalcado que recebeu. $\mathrm{O}$ documento declara que é importante romper com uma visão reducionista sobre a criança, considerando-a como um indivíduo plural. Aparenta buscar um entendimento de que cada um aprende de uma maneira ou, ainda, que cada criança ou jovem podem manipular os currículos e os conhecimentos do modo como cada um é afetado. No entanto, sigamos lendo o texto da BNCC:

A BNCC está estruturada de modo a explicitar as competências que os alunos devem desenvolver ao longo de toda a Educação Básica e em cada etapa da escolaridade, como expressão dos direitos de aprendizagem e desenvolvimento de todos os estudantes [...]. Também se esclarece como as aprendizagens estão organizadas em cada uma dessas etapas e se explica a composição dos códigos alfanuméricos criados para identificar tais aprendizagens (BRASIL 2018, p. 23).

Parece, então, que os discursos da BNCC querem transformar as crianças em leitoras de código de barras. Pense conosco: a criança adentra um centro de educação munida de seu mapa 
a ser decodificado. Para penetrar nos próximos compartimentos do labirinto, é preciso decodificar um código, emitindo, assim, um feixe de luz para conquistar o conhecimento.

De maneira hierárquica, classificatória, prescritiva e regulatória, a BNCC enquadra as crianças, as professoras e os currículos em mecanismos de contenção e regulação. Nas sociedades de controle, o poder torna-se drasticamente biopolítico, já que o biopoder não controla a vida para suprimi-la, e sim para administrá-la, governá-la.

O governo biopolítico precisa conhecer, organizar e controlar a vida, para que ela seja útil aos seus interesses. A produção de saberes é imprescindível ao exercício do biopoder. Isso porque somente pelos saberes é que o poder se exerce positivamente. No esforço de criar sujeitos governáveis usando técnicas de controle, normalização, moldagem das condutas das pessoas, temos na governamentalidade neoliberal a utilização da educação como elemento estratégico para sua legitimação: constituição de indivíduos sujeitados pela formação de seu capital humano, um sujeito competente, hábil e flexível (CARVALHO; SILVA; DELBONI, 2017, p. 492).

Nesse sentido, afirma-se constantemente que, para aprender, é preciso fazer um caminho único, profetizando a saída de todos de um mesmo labirinto, na decodificação incessante dos códigos de comportamento para a aprendizagem universal e ideal. Defende-se a ideia de um corpo orgânico pronto para receber conhecimentos previamente definidos como necessários e importantes, por isso proclama-se que todos precisam chegar ao mesmo resultado. Até se arrisca uma afirmativa de que os currículos podem realizar uma "adaptação" ou mudar um pouco sua ordem e as crianças podem aprender à sua maneira, no respeito a suas diferenças. Isso qualquer documento aceita de prontidão. Contudo, a questão não é essa. O real problema é que se espera que, mesmo de formas muito diferentes, todas as crianças saiam com, pelo menos, a conta do supermercado-escola dando mais ou menos o mesmo valor, pois deverão comprar produtos curriculares que se equiparem na conta final.

Podemos até encontrar nos documentos textos e expressões que advogam o respeito às diferenças, por exemplo: “[...] há diferenças de ritmo na aprendizagem e no desenvolvimento das crianças que precisam ser consideradas na prática pedagógica [...]” (BRASIL, 2018, p. 42), todavia, nas entrelinhas, espera-se que as crianças atinjam, no fim de determinado ciclo, o mesmo tanto de conhecimento, e isso está bem detalhado e especificado na importância que o documento promove aos códigos alfanuméricos. Em outras palavras, cada criança e cada professor até podem trilhar caminhos diferentes, produzir currículos, conhecimentos e linguagens de acordo com os movimentos criados e vividos, porém o ponto de chegada para 
todos deve ser o mesmo. A única saída do labirinto é o fio que conduz até o fim do percurso que precisa ser mais ou menos do mesmo tamanho para todos.

Nessa perspectiva, o labirinto cartesiano pode fazer sentido. Caminhar por ele, aparentemente, pode indicar o melhor a ser trilhado, visto que se subentende o que é preciso aprender para um futuro imprevisível.

Entretanto, não é possível antever como o outro aprende. No que concerne às questões dos currículos e dos processos de aprenderensinar, apostamos no que acontece no meio, ou nas dobras. Dobras e redobras que atravessam os corpos no encontro de formas singulares de aprender e viver. Justamente as dobras é que tornam os códigos quebrados, são dobras e redobras. Por exemplo, na sequência de códigos alfanuméricos, “[...] cada objetivo de aprendizagem e desenvolvimento é identificado por um código alfanumérico [...]. O último par de números indica a posição da habilidade na numeração sequencial do campo de experiências para cada grupo/faixa etária" (BRASIL, 2018, p. 26). Mas quem pode mensurar o grau de habilidade por uma indicação numérica progressiva? Os documentos podem até sugerir que a aprendizagem seja definida por um código, mas ela não cabe em um código, pois os códigos alfanuméricos fazem dobras e redobras que vão ao infinito.

Nos processos de subjetivação e no encontro com os signos aprendentes, cada criança viverá o encontro com um signo em seu corpo intensivo, e isso movimentará seu pensamento em processos de diferenciação aprendente, produzindo dobras que caminham da virtualidade para sua atualização e realização. Portanto, variações de aprendizagem na produção de conhecimento, linguagens, afetos, afecções e fabulações derivam-se ao infinito, de modo que não há como prever ou definir os percursos a se caminhar pelo labirinto escola-mundo.

Nesse sentido, o labirinto para nós não pode ser entendido de modo cartesiano, como um trajeto a ser seguido, com definições e determinações. Compreendemos o labirinto a partir das problematizações de Deleuze, em seu livro A dobra: Leibniz e o Barroco. Leibniz utiliza o labirinto para explicar o conceito de espaço. O espaço é, assim, constituído como um labirinto em número infinito de dobras, algo parecido com uma cidade que se compõe de quadras, casas, edifícios, quartos, móveis. São, assim, sempre dobras dentro de dobras, dobras que conformam espaços como um origami, “[...] a arte da dobradura do papel” (DELEUZE, 1991, p. 18).

O labirinto é, portanto, um cruzamento de caminhos, percursos, derivações e bifurcações para os quais nunca é possível traçar um único plano ou um trajeto previamente definido, 
justamente porque, nessas tramas, ou dobras, algo sempre não se encaixará, vai compor outros planos ou mundos possíveis que se derivarão em outros trajetos e dobras. Por essa razão, Deleuze (1991, p. 17) afirma que “[...] o menor elemento do labirinto é a dobra [...]”, isso porque se compreende que o labirinto é múltiplo, uma vez que ele é dobrado de muitas maneiras, visto que as tramas que o compõem se modificam e se metamorfoseiam uma infinidade de vezes, "Eis por que a desdobra nunca é o contrário da dobra, mas é o movimento que vai de umas dobras às outras" (DELEUZE, 1991, p. 140). Dessarte,

[...] há sempre uma inflexão que faz da variação uma dobra e que leva a dobra ou a variação ao infinito. A dobra é a potência como condição de variação, como se vê no número irracional que passa por uma extração de raiz e no quociente diferencial que passa pela relação de uma grandeza e de uma potência. A própria potência é ato, é o ato da dobra (DELEUZE, 1991, p. 34).

Desse modo, caminhar pelo labirinto corresponde à própria capacidade de variação, de multiplicidade na potência de dobrar-se infinitas vezes. Diz respeito a percorrer trilhas e bifurcações que se atualizarão no encontro entre os corpos. Tudo se dobraria à sua maneira. Cada dobra do labirinto dobrar-se-ia de acordo com as forças pelas quais é capaz de se expressar como a própria potência do ato. Nesse sentido, "O plano de imanência toma do caos determinações, com as quais faz seus movimentos infinitos ou seus traços diagramáticos” (DELEUZE; GUATTARI, 1992, p. 68).

Isso posto, podemos supor que existem multiplicidades de planos que se entrecruzam, de maneira que se dispõem, nesses mundos possíveis, criados e fabulados, de movimentos imanentes que se permitem dobrar e redobrar juntos. O caos seria, então, “[...] o conjunto dos possíveis, isto é, todas as essências individuais, visto que cada uma tende à existência por sua conta; mas o crivo só deixa passar compossíveis e a melhor combinação de compossíveis" (DELEUZE, 1991, p. 118).

Não podemos, portanto, pensar em corpos que podem ser divididos, ou seja, que sejam compartimentalizados em códigos, em momentos para aprender tal assunto e depois outro; ao contrário, os corpos estão dobrados e redobrados como uma folha de papel que se redobra em todas as direções. "Ora é a dobra do infinito, ora a prega da finitude que dá uma curvatura ao lado de fora e constitui o lado de dentro" (DELEUZE, 1998, p. 104).

Logo, tudo passa em nível molecular, como se, quando percorremos o labirinto, as coisas acontecessem aos milhares, em matilha, em corpos intensivos que são vários, são 
formados cada qual de inumeráveis partes. Os corpos, assim, dividem-se em partes cada vez menores, “[...] sem que o corpo jamais se dissolva em pontos ou mínimos [...]” (DELEUZE, 1991, p. 17), pois nunca são iguais, não são únicos, mas estão sempre juntos, dobrando-se infinitamente. Por tais motivos, não há como definir os caminhos que as crianças percorrerão no labirinto das aprendizagens. É um engano acreditar que podemos seguir por caminhos uniformes e padronizados, agarrados ao fio de Ariadne na pretensão de garantir que todos consigam decifrar os códigos alfanuméricos. Os mundos possíveis dobram-se, redobram-se e produzem nós e rupturas no fio que supõe guiar um caminho.

Talvez, por isso, quando um corpo é afetado por uma virtualidade nos mundos possíveis, cria dobras que envolvem outras dobras em desdobramento, "Produz-se entre as duas um deslocamento que faz do envoltório a razão da dobra: o que está dobrado é incluído, o inerente. Dir-se-á que o que está dobrado é somente virtual e que só existe atualmente em um envoltório, em algo que o envolve" (DELEUZE, 1991, p. 40). No encontro das singularidades, portanto, o processo de atualização das virtualidades operará por distribuição, mas o processo de realização operará por semelhança (DELEUZE, 1991). Logo, no encontro entre os corpos singulares, as fabuloinvenções (GONÇALVES, 2019) das crianças ocorrerão por contágio, em processos de afetos e afecções, nos quais os corpos envolvidos se permitirão dobrar o labirinto em uma multidão de possibilidades.

Nas dobras, os mundos possíveis são produzidos. Eis a potência para pensarmos o labirinto e suas infinitas possibilidades de caminhos, trajetos e bifurcações. Nunca se pode premeditar como as dobras serão criadas, pois o caos rasga as tramas e séries que as compõem e "[...] lá onde as séries divergem começa outro mundo, incompossível com o primeiro" (DELEUZE, 2006, p. 114-115), que se dobrará ao infinito, criando, assim, outros mundos possíveis dos quais as dobras produzirão outros caminhos em que poderemos habitar.

São trajetos e percursos que colocam em problematização as prescrições e as homogeneizações. As dobras criam, assim, rupturas nos mecanismos de controle que anseiam por compartimentalizar os conhecimentos, as aprendizagens e as linguagens em códigos previsíveis. Fazem dobras, redobras, fazem dobrinhas.

As fabuloinvenções das crianças são, então, a própria potência da dobra, que criará mundos compossíveis, ou seja, “[...] dois acontecimentos são compossíveis quando as séries que se organizam em torno de suas singularidades se prolongam umas às outras em todas as 
direções, incompossíveis quando as séries divergem na vizinhança das singularidades componentes" (DELEUZE, 2006, p. 177-178).

Propor, portanto, a multiplicidade do labirinto que se produz cria, fabula pelas dobras, em séries divergentes e convergentes de mundos compossíveis e incompossíveis, é sugerir que:

Não nos encontramos mais diante de um mundo individualizado constituído por singularidades já fixas e organizadas em séries convergentes, nem diante de indivíduos determinados que exprimem o mundo. Encontramo-nos agora diante do ponto aleatório dos pontos singulares, diante do signo ambíguo das singularidades, ou antes diante do que representa este signo e que vale para vários desses mundos, e, no limite, para todos, para além das divergências e dos indivíduos que os povoam (DELEUZE, 2006, p. 118).

Se o menor elemento do labirinto é a dobra, isso faz com que problematizemos que o labirinto, ao se produzir em dobras e redobras, atualiza-se nas linguagens, conhecimentos, afetos e afecções, de modo que, ao realizar-se, produz no plano real o que estava em virtualidade, criando, assim, seus próprios percursos de caminhada.

Caminhar para chegar ao fim do labirinto, ou seguir incansavelmente para o centro em busca do Minotauro, carrega o falso sentido de que, ao chegar a determinado ponto, vamos encontrar uma suposta verdade ou, ainda, o conhecimento, conforme propõe a BNCC, indicando o currículo como conteúdo a ser percorrido por um caminho designado. No entanto, as crianças em suas brincadeiras, na produção de currículos e aprendizagens, têm nos ensinado a multiplicidade de caminhos a trilhar, embaralhando os códigos, dobrando e dobrando os labirintos dos centros de educação infantil.

\section{BRINCAR CABE EM UM CÓDIGO E/OU EM UM CÓDIGO PREVIAMENTE DETERMINADO?}

A pergunta pode até causar um pouco de estranhamento. Afinal, é possível codificar uma intensidade? $\mathrm{Na}$ aspiração de entender, classificar e descrever as brincadeiras das crianças, algumas práticas discursivas transformam o brincar em comportamentos universais e classificam a fabulação como mero decalque, o que torna aparentemente possível codificar as brincadeiras infantis.

Nesse sentido, define-se o brincar como imitação, decalque, conformação entre sujeito e objeto, por isso se deseja discorrer como e por que as crianças brincam. Então, munido desses 
Programa de Pós-Graduação em Educação: Currículo

mecanismos de descrição sobre as crianças, busca-se enquadrá-las em códigos, em etapas, em fases de uma vida meramente comportamental. Assim, o brincar, às vezes, não passa de um clichê, pois só é visto como uma prática útil ou essencial, quando associado a uma aprendizagem pedagógica normativa. Contudo, até que ponto entendemos a potência da brincadeira como possibilidade de aprendizagem? Como as professoras incorporam a brincadeira em suas práticas pedagógicas? Como as crianças aprendem em suas brincadeiras?

Deleuze (1988) já nos sinalizava que ninguém consegue antever como o outro aprende nem pode determinar como uma criança brinca. Brincar é intensidade, é devir que atravessa os corpos e produz outra coisa que não foi pensada ou definida previamente.

Quando buscamos normatizar as brincadeiras, sempre haverá escapes, burlas e produções de sentido pelas crianças que derivarão ao infinito. São dobras em mundos compossíveis que se atualizam no encontro entre os corpos. A potência do brincar está no encontro, na ação fabuladora que se atualiza em intensidades inventivas que criam nos corpos outros modos de produzir aprendizagens, indicando que brincar não pode ser codificado, que a intensidade da criação e da invenção pode sempre apontar novos e impensáveis caminhos para os currículos.

Como no caso de um momento de roda, no início da rotina diária. A professora buscou uma bola produzida pelo grupo, feita de papel e fita adesiva, e sugeriu uma brincadeira que consistia em sentar as crianças em círculo, e uma delas jogaria a bola para a outra utilizando apenas as pernas. Quem encostasse as mãos sairia da brincadeira. Quando as regras não eram cumpridas, a professora e algumas crianças logo fechavam o círculo, retirando a criança da roda. A brincadeira seguia, mas um menino que havia furado as regras permanecia à espreita, andando em volta do círculo de crianças; e, quando a bola era arremessada para longe, era ele que ia buscá-la, sentava-se no chão - fora do círculo - e jogava com os pés a bola para alguma criança. Uma vez ou outra, o menino perguntava:

- Tia, posso voltar a brincar?

Com uma resposta negativa, logo percebia que poderia, naquele momento, envolver-se de outro modo. Sem dúvida, era um dos mais entusiasmados com a brincadeira. Ele fixava seus olhos na bola de papel e torcia para que alguém a arremessasse para bem longe. $\mathrm{E}$ ali ficamos, por longo período, e outras crianças saíram da brincadeira, mas o menino não desistia: criou uma dobra na brincadeira, produziu outros modos, envolveu as outras crianças que saíram da 
roda. Por isso, “[...] não são os começos nem os fins que contam, mas o meio. As coisas e os pensamentos crescem ou aumentam pelo meio, e é aí onde é preciso instalar-se, é sempre aí que isso se dobra" (DELEUZE, 1992, p. 200).

Portanto, como podemos aferir que tal modo de brincar pode enquadrar-se em um código? Ou que tal habilidade pode ser descrita e encaixada em uma etapa da vida intensiva? Como avaliar uma intensidade? A potência das aprendizagens está nos encontros entre os corpos, nas propostas que apresentamos e nos caminhos construídos e desconstruídos. Brincar, portanto, é uma condição da vida intensiva, são corpos que buscam por composição, criação e fabulação, e isso nos convoca a pensar a brincadeira sob outra perspectiva...

\section{UMA VIDA QUE BRINCA}

A criança é um conjunto de potência devindo, desdobrando-se ao infinito nas múltiplas experiências que traça com os signos que perpassam seu mundo. Ela borra os dispositivos de controle que buscam descrevê-la. Nas brincadeiras que criam, as crianças sempre escapam das descrições e das prescrições do que e como brincar.

Por mais que os adultos falem que não podem brincar, por exemplo, de polícia e ladrão, elas sempre o fazem. Quando menos se espera, lá estão elas subindo a pedra "proibida" para pular o mais alto que conseguirem ou produzir armas com brinquedos de encaixe. Elas furam os mecanismos de controle e sofrem os castigos consequentes. Por qual motivo elas buscam determinadas brincadeiras que as privam, muitas vezes, do "tempo livre"? Por que, por mais que os adultos determinem o que não fazer, elas insistem?

Brincar não corresponde à cognição, muito menos a zonas de desenvolvimento ou etapas a serem atingidas. Parece-nos que não há uma racionalidade que direciona as crianças, que as condicionam apenas às brincadeiras permitidas. Elas se recusam a percorrer o labirinto cartesiano, criam os próprios percursos, fazem dobras e redobras, justamente porque, quase sempre, brincar corresponde a movimentar-se, é intuição, é devir, é fabulação. Brincar transcende a cognição cartesiana. Brincar não cabe em zonas, em estágios, em códigos alfanuméricos, pois brincar é a própria potência da vida que coloca as virtualidades em constante atualização. 
A marca das crianças são as intensidades em que vivem com seus corpos. Assim sendo, podem entrar em diferentes sintonias e delas sair, além de realizar diferentes conexões em que vivem. Para elas, não há fronteiras. São corajosas ao experimentarem a vida. Nós, adultos, temos muito que aprender com as crianças, apesar do nosso desejo, quase desesperado, de descrevê-las e de enquadrá-las como um "pré-adulto", ao interpretarmos suas atitudes e comportamentos por meio de roteiros. Elas nos lembram o tempo todo que ser criança não é questão de faixa etária. É questão de intensidade, de experenciar a vida pelo tempo aión, de vivenciar o devir-criança em nossa docência.

Massumi (2017), em seu livro intitulado O que os animais nos ensinam sobre política, afirma que a brincadeira é uma condição da própria animalidade, traçando, assim, problematizações sobre a brincadeira como um processo intuitivo, instintivo, criativo e político.

De modo geral, os momentos que as crianças têm para brincar estão quase que majoritariamente organizados em tempos de pátio ou mesmo nas salas de aula. Nesses momentos, não há, normalmente, nenhuma orientação das professoras. O tempo é "livre" para brincar. As professoras organizam-se para acompanhar as crianças e zelar para que, durante a brincadeira, elas não se machuquem.

Independentemente do lugar em que o "tempo livre" é oferecido, as crianças não ficam paradas e, quando paradas, não há garantia de que o pensamento não esteja em processos de criação e de invenção. Não é raro nos achegarmos a alguma criança mais distanciada, em aparente solidão, e nos surpreendermos com suas produções, como no caso em que um menino observava uma família de formigas, investigava as ranhuras no chão, o detalhe das folhas e admirava como elas, as formigas, selecionavam uma coleção de sementes. Outro exemplo: uma criança olhava para o céu acompanhando o deslocar de um avião, mas, ao nos aproximarmos, ficamos surpresas:

- Olha, tia, um avião!

-É mesmo!

- Ele está bem alto, né?

- Sim, muito alto!

- O que é aquilo branco que ele está soltando?

- Não sei, o que você acha que é?

- Não sei. Será que está marcando o caminho de volta? 
E, assim, um simples momento "livre" transforma-se em potência para a criação das fabuloinvenções das crianças, uma vez que elas apontam direções que não podemos predeterminar, muito menos descrever previamente. São da ordem do acaso, do acontecimento. Em alguns momentos, éramos convidadas a fabular. No envolvimento que as crianças criavam, transformávamo-nos em bruxas, princesas, monstros, super-heróis e animais.

- Eu sou uma bruxa muito má, moro neste castelo - apontava para o brinquedo de plástico que permite às crianças subir.

- Cuidado, ela é uma bruxa! Corram! - e saem as crianças correndo da temível bruxa.

- Miau, miau! Como é o seu nome? - perguntei.

- Não vê, tia, que ele é um gato, ele só mia, é o nosso gatinho.

As crianças acariciam a cabeça do meninogato e seguem a brincadeira. $\mathrm{O}$ meninogato começa a imitar o animal felino e, com a cabeça, acaricia nosso ombro, produz uma lambida. Não se sabe mais se é um gato ou um menino. A potência da fabulação o transformou em um meninogato.

Talvez, ao vivenciarmos um momento como esse, sejamos lançados a imagens do pensamento que remetem à representação. Porventura, podemos supor que a criança tenha um gato, por isso reproduz o comportamento do felino. Ocasionalmente, tentamos associar a imitação do meninogato às brincadeiras que encenam a vida dos adultos, como as brincadeiras com panelinhas, mãe-filho, entre outros exemplos. No entanto, nunca é só imitação, é também outra coisa, pois "[...] só se pode imitar aquilo que se é quase capaz de inventar. Aquilo que é sentimentalmente considerado imitação é, na verdade, a catalisação de um germe de invenção" (MASSUMI, 2017, p. 154).

Logo, as crianças não precisam de recursos para brincar. A brincadeira acontece independentemente do que é oferecido, pois o movimento do pensamento é suficiente para que entrem em processos de desterritorialização, dobrando-se e redobrando-se ao infinito. Brincar é da ordem do acaso. É um ato intuitivo visionário. É um ato imanente. "O que as crianças veem: a imanência de uma vida" (MASSUMI, 2017, p. 156).

Por esse motivo, mesmo seguindo brincadeiras pedagógicas, ou em momento "livre", o brincar não cabe em códigos, pois brincar é instintivo, é intuitivo, “[...] o próprio instinto dá sinais de elasticidade, e mesmo de uma criatividade que se poderia rotular de 'artística"" (MASSUMI, 2017, p. 10). Portanto, na brincadeira, as crianças fabulam, criam personagens, 
exploram e põem em dúvida os próprios códigos de comportamento da psicologia do comportamento. Se estão em virtualidade do próprio plano de imanência, nunca se pode prever como será uma brincadeira, ou os motivos pelos quais as crianças brincam daquele modo, e não de outro. $\mathrm{O}$ virtual atualiza-se na própria brincadeira que se desdobra ao infinito.

Entender, portanto, a brincadeira como uma condição de nossa animalidade, a qual perpassa por um processo intuitivo, de criação e de invenção imanente, distancia-se, e muito, das concepções de infância, quando considerada como um estado de incompletude relacionada com uma temporalidade cronológica. Não, a infância, em nossa perspectiva, não é uma questão cronológica, e sim de experiência, por isso é preciso ampliar os horizontes da temporalidade (KOHAN, 2007).

O habitante do plano de imanência, a criança, é vida, uma vida. Ela não pertence à vida. É uma vida em sua máxima potência. Suas virtualidades atualizam-se no plano de imanência e se desdobram em processos de aprendizagem. Dessarte, pensar a infância como experiência é considerar que as crianças se expressam na própria linguagem, produzem mundos, inventam e fabulam.

- Olha, tia, como eu subo na pedra!

A criança pula o mais alto que consegue. No ato do pulo, fecha os olhos e parece que sente todo o corpo livre, em movimento, sensibiliza-se à própria brisa que perpassa seu corpo. E, mesmo antes de bater no chão, já sai correndo, querendo pular novamente.

- Eu pulo muito alto! Sou o Hulk!

- Eu sou o Flash, tenho muita energia. Olha como eu corro rápido! E saiu a meninaflash correndo pelo pátio.

- Realmente você é muito rápida! - respondemos. A criança, não satisfeita, retrucou:

- Mas minha energia ainda não acabou.

E mais uma vez saiu correndo sob o sol quente, com os pés no cimento e o suor no rosto escorrendo.

Depois de cerca de umas seis voltas, a criança voltou:

- Agora a minha energia acabou, preciso de água para repor a minha energia.

E saiu a menina em busca de combustível.

Um grupo de crianças corre pelo pátio que recentemente ganhou nova pintura: uma tonalidade vermelha. 
- Cuidado, com a lava do vulcão! Se protejam! Fujam!

- Cuidado, corra bem rápido! Você vai se queimar.

Correram as crianças em busca de um lugar seguro.

- Cuidado, é lava... está muito quente!

- Não pise aí, você vai se machucar!

- Corra rápido, suba aqui, você precisa se salvar.

Não há o que descrever, classificar, comparar. É uma vida que pede passagem, que se atualiza no encontro com outros corpos, que solicita a invenção. Devindas, as crianças criam asas celestes que fabulam diferentes mundos. Pensar, portanto, é algo que se produz entre o possível e o impossível, entre o lógico e o ilógico, entre o saber e o não saber. Se ficássemos situados na clareza do absolutamente lógico, se percorrêssemos o labirinto cartesiano descrevendo incansavelmente as crianças e suas brincadeiras, muito provavelmente não teríamos materiais para criar (KOHAN, 2007). Brincar corresponde à intuição, à invenção e à criação, justamente porque brincar é experiência. Brincadeiras são processos de adaptação na produção de linguagens e conhecimentos nos quais brincar desempenha um papel de aprendizado.

Massumi (2017) inverte a lógica de uma opinião dominante que entende a brincadeira animal como um treinamento para o futuro. Aqueles que trilharem o caminho cartesiano dirão que a brincadeira, para ter alguma utilidade, deverá ter uma exata correspondência aos movimentos de combate. Contrariando tal pensamento, o autor canadense propõe que, no entusiasmo dos corpos que brincam, há um poder de variação. Por exemplo, no caso dos animais, as mordidas nas brincadeiras de combate. Assim, na lacuna entre o lúdico e o análogo, abre-se espaço para a improvisação, o que faz da brincadeira " [...] verdadeiro laboratório de formas em ação no vivo" (MASSUMI, 2017, p. 28). É a mais-valia da vida que corresponde à mais-valia da inventividade, da criação da novidade, o que, durante o combate, oferece ao animal a vantagem.

Um gesto cuja forma é moldada como uma função de fim reconhecidamente instrumental é um gesto normatizado antes mesmo de sua execução, e um gesto normatizado é um gesto previsível. Se o aprendizado ficasse restrito à modelagem da forma de um ato instintivo antes de sua execução instrumental, seria perigosamente desadaptativo, moldaria os alunos para a morte. Ruyer sustenta que o poder de improvisar é uma dimensão necessária em qualquer instinto (MASSUMI, 2017, p. 28-29). 
Moldar-se-iam os alunos ou as crianças para a morte, justamente porque o combate é da ordem do imprevisível. A potência do combate ou da brincadeira está precisamente na capacidade de improvisar, visto que nunca se sabe onde, quando ou com que começará a brincadeira. Desse modo, “[...] não é a brincadeira que é moldada na forma do combate, é a forma do combate que é modulada pela brincadeira" (MASSUMI, 2017, p. 29).

A brincadeira, assim, corresponde ao desdobramento cósmico da ordem do imensurável, acontece exatamente pela polifonia de vozes virtuais que buscam atualização. Os combates ou brincadeiras surgem nas formas de vidas em ação que procuram a invenção, a improvisação, as linhas de fuga. Quando uma virtualidade se atualiza, logo outra entra no jogo da brincadeira, atualizando-se, e assim seguem. Dessarte, as crianças mudam de brincadeira, envolvem-se em determinado acontecimento e logo são atravessadas por outras virtualidades que almejam por atualização. Improvisam. Criam. Aprendem. Adaptam-se. Fabulam.

\section{CONCLUSÕES PROVISORIAMENTE FINAIS: SOBRE A (IM)POSSIBILIDADE}

\section{DE APRENDIZAGENS BRINCANTES SEREM REDUZIDAS A CÓDIGOS ALFANUMÉRICOS DA BNCC PARA A EDUCAÇÃO INFANTIL}

A criança cronológica, um dia, tornar-se-á adulta e enquadrar-se-á no agenciamento maquínico de subjetividades que a sociedade e as instituições nos impõem. O devir-criança (DELEUZE; GUATTARI, 1997), porém, é a resistência a esses agenciamentos. São movimentos fáceis e intensos para as crianças, mas difíceis para os adultos. Em contrapartida, o devir-criança sobrevém ao adulto, que ri do inesperado, afeta-se por signos simples, passa a cartografar outros modos de existência, contagia-se pelas virtualidades das crianças e atualizaa em uma vida imanente. $\mathrm{O}$ devir-criança é o próprio Minotauro que se recusa a sair do labirinto e, ao encontrá-lo, em vez de sair correndo, abraça-o, contagia-se com sua potência. Permite-se afetar e ser afetada pelos encontros, pelos trajetos moleculares, cria linha de fuga e fabula invenções.

Portanto, o devir-criança não é uma questão de fingir ou imitar uma criança, mas de experenciar a intensidade da criança para, assim, "[...] inventar novas forças ou novas armas" (DELEUZE; PARNET, 2004, p. 5), pois “[...] as crianças são rápidas porque sabem deslizar entre" (DELEUZE; PARNET, 2004, p. 27). Acreditamos, então, que o devir-criança é potência 
para pensarmos as infâncias. Em devir, as crianças podem inventar novos mapas para os processos curriculares, ao extraírem a diferença do fundo da imagem dogmática do pensamento, inventando novos mapas para nossos processos curriculares, como ilustra o registro cartográfico a seguir...

Era primavera, um dia de temperatura amena devido à chuva que caíra à noite, tornando a manhã agradável. $\mathrm{O}$ chão estava úmido e algumas poças de água mudavam a corriqueira paisagem de um centro de educação infantil. O sol estava começando a esquentar e aquelas pequenas poças que faziam jazidas pela topografia irregular do pátio começavam a evaporar. Um menino fabulador percorrendo aquele espaço aproximava-se de algumas pessoas e timidamente enunciava alguma coisa que nem todos eram capazes de ouvir. Tentou, insistiu muitas vezes, até que, ao se aproximar mais, exclamou de maneira mais intensiva:

- Tem um bicho no nosso pátio!

Por causa da potência da sua fala, fomos à procura do temido bicho com nossas lanternas. Em um dado momento, ele apontou com um foco de luminosidade as garras molhadas impressas em uma superfície: “Aqui, achei uma pista, o monstro deixou as suas garras!” exclamou. Aquele dia poderia ter sido um dia como qualquer outro, mas aquelas poças d'água deram outro movimento àquele labirinto escolar. Não houve outra saída, focalizamos aquelas garras e começamos a procurar aquele horrendo monstro. Outras pequenas luzes, as quais viram aquele monstro que habitava a virtualidade se atualizar para o real, começaram a se aproximar e, como um enxame de vaga-lumes, vários focos de visibilidade começaram a aparecer. A partir daí, muitos outros monstros foram criados por meio de pegadas molhadas que marcaram todo aquele território.

Podemos, com as fabuloinvenções das crianças, criar outros percursos linguísticos e conhecimentos que não foram pensados e planejados. Isso nos possibilita indicar pontos de bifurcação e intercessão pelo labirinto curricular, arriscando-nos na produção de currículoscristalinos dentro de currículos-orgânicos.

Problematizar a produção de currículos-orgânicos e cristalinos é fazer como Deleuze nos ensinou: roubar os conceitos! Para o autor, “[...] roubar é o contrário de plagiar, de copiar, de imitar ou de fazer como" (DELEUZE; PARNET, 2004, p. 6). Nesse sentido, o autor, ao questionar a imagem, faz um convite a pensá-la sob dois regimes: um orgânico e um cristalino.

O primeiro refere-se às descrições. Chamemos de "orgânica" uma descrição que supõe a independência de seu objeto [...]. Chamamos, ao contrário, 
"cristalina" a descrição que vale por seu objeto, que o substitui, cria-o e apagao a um só tempo, como diz Robbe-Grilet, e sempre está dando lugar a outras descrições que contradizem, deslocam ou modificam as precedentes (DELEUZE, 2018, p. 185).

O currículo-orgânico, então, seria aquele que indica uma prescrição, como os manuais e códigos impressos na BNCC. Por sua vez, os currículos-cristalinos seriam aqueles que deslocam as prescrições e apostam em processos de criação e de invenção: aqueles que estão em constantes processos de inter-relação, mesmo que os processos de fabulação dos currículoscristalinos estejam em virtualidade.

A questão, portanto, é que, ao propormos as enunciações infantis como possibilidades de atualização dos currículos virtuais, fazemos um convite aos processos deslizantes das criações e invenções infantis, nos quais justamente a potência está nas fabulações das crianças. Quando fabulam e gaguejam a língua, buscam a atualização do virtual para o plano de imanência, fazendo com que o falso que habita o virtual se funda ao verdadeiro em sua atualização. A fabulação, portanto, opera na atualização do virtual e a invenção torna-se potência de criação.

Ao fabularem, criam um devir-outro que envolve a passagem entre categorias, formas de existência e corpos distintos. Logo, os elementos estáveis, no nosso caso os currículos, são colocados em "desequilíbrio metamórfico" (BOUGE, 2011, p. 21). As crianças inventam linguagens e conhecimentos. Nesse sentido, a fabulação também funciona como experimentação do real por meio das “[...] intervenções no universo de seus ambientes políticos, institucionais, naturais e materiais" (BOUGE, 2011, p. 22). Sendo assim, há um confronto entre o presente e o passado, “[...] já que o mundo em que vivemos é produto de uma história complexa de acontecimentos que moldaram, e continuam moldando, o presente" (BOUGE, 2011, p. 23). Portanto, quando as crianças fabulam, criando suas fabuloinvenções, experimentam o real - o currículo pensado pelas professoras - e transformam o momento presente em currículos em potencial a serem produzidos por criançasprofessorascrianças.

Desse modo, pensamos que, quando as crianças entram em contato com as problematizações das professoras, elas fazem os currículos variar, produzindo enunciados diferenciais, visto que a “[...] função fabuladora não consiste em imaginar nem projetar um eu. Ela atinge, sobretudo, visões, eleva-se até devires e potências [...]” (DELEUZE, 1997, p. 13), efetuando, assim, um delírio menor da língua. Não se limitam a fazer conexões com regimes 
de verdade ou de representação. Até se utilizam das convenções linguísticas formais, mas fazem conexões inusitadas pela sua sensibilidade de se afetarem com as forças do mundo. Traçam, assim, aprendizagens singulares e diferenciais que produzem os próprios labirintos de conhecimentos.

Quando problematizamos que a brincadeira não cabe em códigos, é mesmo para tentar pensar nessa multiplicidade de virtualidades que transitam pelo plano de imanência. Uma vida, uma multidão, afetará uma multiplicidade de virtualidades, almejando um combate para se atualizar em aprendizados na produção de linguagens e conhecimentos.

Assim, é uma vida que brinca...

\section{REFERÊNCIAS}

BOUGE, Ronald. Por uma teoria deleuziana da fabulação. In: AMORIM, Antonio Carlos; MARQUES, Davina; DIAS, Susana Oliveira. Conexões: Deleuze e vida e fabulação e... Campinas: Editora ALB, 2011. p. 17-36.

BRASIL. Ministério da Educação. Base Nacional Comum Curricular: educação é a base. Brasília, DF, 2018. Disponível em: http://basenacionalcomum.mec.gov.br/versaofinal_site.pdf. Acesso em: 20 abr. 2020.

CARVALHO, Janete Magalhães; SILVA, Sandra Kretli da; DELBONI, Tânia Mara Zanotti Guerra Frizzera. A Base Nacional Comum Curricular e a produção biopolítica da educação como formação de "capital humano". Revista e-Curriculum, São Paulo, v. 15, p. 481-503, 2017. Disponível em:

https://revistas.pucsp.br/index.php/curriculum/article/view/27679/23024. Acesso em: 20 abr. 2020.

DELEUZE, Gilles. Diferença e repetição. Tradução Luiz B. L. Orlandi e Roberto Machado. Rio de Janeiro: Graal, 1988.

DELEUZE, Gilles. A dobra: Leibniz e o Barroco. Tradução Luiz B. L. Orlandi. Campinas: Papirus, 1991.

DELEUZE, Gilles. Conversações. Tradução Peter Pál Pelbart. Rio de Janeiro: Editora 34, 1992.

DELEUZE, Gilles. Foucault. Tradução Claudia Sant'Anna Martins. São Paulo: Brasiliense, 1998.

DELEUZE, Gilles. Lógica do sentido. Tradução Luiz Roberto Salinas Fortes. 4. ed. São Paulo: Perspectiva, 2006. 
DELEUZE, Gilles. Cinema 2: a imagem tempo. Tradução Eloisa Araújo Ribeiro. São Paulo: Editora 34, 2018.

DELEUZE, Gilles; GUATTARI, Felix. O que é a filosofia? Tradução Bento Prado Jr. e Alberto Alonso Muñoz. Rio de Janeiro: Editora 34, 1992.

DELEUZE, Gilles; GUATTARI, Felix. Mil platôs: capitalismo e esquizofrenia. Rio de Janeiro: Editora 34, 1997. v. 4.

DELEUZE, Gilles; GUATTARI, Felix. Kafka para uma literatura menor. Tradução Cíntia Vieira da Silva. Revisão da tradução Luiz B. Orlandi. 1. ed. 3. reimp. Belo Horizonte: Autêntica, 2014.

DELEUZE, Gilles; PARNET, Claire. Diálogos. Tradução José Gabriel Cunha. Lisboa: Relógio d'Água, 2004.

GONÇALVES, Camilla Borini Vazzoler. As fabuloinvenções das crianças nos agenciamentos dos currículos. Orientador: Janete Magalhães Carvalho. 2019. $155 \mathrm{f}$. Dissertação (Mestrado em Educação) - Universidade Federal do Espírito Santo, Vitória, 2019.

GUATTARI, Felix; ROLNIK, Suely. Micropolitica: cartografias do desejo. Petrópolis: Vozes, 2005.

KOHAN, Walter Omar. Infância, estrangeiridade e ignorância. Belo Horizonte: Autêntica, 2007.

MASSUMI, Brian. O que os animais nos ensinam sobre política. São Paulo: n-1 Edições, 2017.

Recebido em: 16/05/2020

Aprovado em: 25/09/2020 